\title{
CT Evaluation of Apical Canal Transportation Associated with Stainless Steel Hand Files, Oscillatory Technique and ProTaper Rotary System
}

\author{
Mateus Silveira Martins HARTMANN ${ }^{1}$ \\ Vânia Regina Camargo FONTANELLA ${ }^{2}$ \\ José Roberto VANNI ${ }^{1}$ \\ Volmir João FORNARI ${ }^{1}$ \\ Fernando Branco BARLETTA ${ }^{2}$
}

\author{
${ }^{1}$ Department of Endodontics, Uningá Dental School and IMED Dental School, Passo Fundo, RS, Brazil \\ ${ }^{2}$ Department of Dentistry and Endodontics, Dental School, Lutheran University of Brazil, Canoas, RS, Brazil
}

\begin{abstract}
This study used computed tomography (CT) to compare apical canal transportation in mesiobuccal canals of maxillary molars prepared with different techniques. Sixty teeth were assigned to 3 groups $(n=20)$, according to the technique used for root canal instrumentation: hand instrumentation with K-Flexofiles, K-Flexofiles activated by an oscillatory system and ProTaper NiTi rotary system. Pre and postinstrumentation CT images were obtained $3 \mathrm{~mm}$ short of the apical foramen and were superimposed to compare canal transportation. Data were analyzed statistically by ANOVA and Tukey's test using the SPSS software $(\alpha=0.05)$. In the buccal direction, the manual technique produced significantly less canal transportation than the oscillatory technique $(\mathrm{p}<0.05)$ and both were similar to the rotary technique $(\mathrm{p}>0.05)$. In the distal and distopalatal directions, the oscillatory technique produced more canal transportation $(\mathrm{p}<0.05)$. In the mesiopalatal direction, the oscillatory technique produced more canal transportation than the manual technique ( $\mathrm{p}<0.05$ ), and both were similar to the rotary technique $(\mathrm{p}>0.05)$. In conclusion, all techniques produced canal transportation, and the oscillatory technique produced the greatest removal of root dentin toward the innerside of the root curvature.
\end{abstract}

Key Words: canal transportation, computed tomography, Endodontics, root canal instrumentation.

\section{INTRODUCTION}

Acquiring of a continuously tapered funnel shape is a prerequisite for adequate filling of root canal systems. This is done by adequate biomechanical debridement in order to remove canal contents, specifically microorganisms, while preserving root canal anatomy (1). Several techniques have been developed to minimize errors deriving from root canal instrumentation, such as zip, ledge, or perforation, particularly in narrow curved canals. Nevertheless, because of internal anatomy complexity, there are still difficulties in preparing adequately curved and flattened root canal systems (2).

The introduction of nickel-titanium (NiTi) instruments allowed a safer and easier preparation of canals with complex anatomical characteristics (3). Rotary techniques have been significantly improved over the last years (3), especially with the development of instruments with different designs. Along with the improvement of rotary instrumentation, another type of automated system has been reintroduced to dental practice. The oscillatory or reciprocating mechanical systems, such as Anatomic Endodontic Technology (Ultradent Products Inc., South Jordan, UT, USA), M4 (Kerr - SybronEndo, Orange, CA, USA), 3LD (KaVo, Biberach, Germany), TEP E-10 and 16R (NSK Nakanishi, Tochigi-ken, Japan), may be driven by electric or pneumatic engines and have the advantage of being used with both stainless steel and NiTi hand files.

Regardless of the technique, biomechanical preparation of root canals invariably leads to dentin removal from the canal walls due during shaping procedures (1). However, excessive dentin removal in a single direction or not equidistantly from the main tooth

Correspondence: Prof. Dr. Mateus Silveira Martins Hartmann, Rua Mascarenhas de Moraes, 115/402, 99025-040 Passo Fundo, RS, Brasil. Tel: +55-54-9961-8777. Fax: +55-54-3312-6964. e-mail: mateushartmann@terra.com.br 
axis causes apical canal transportation.

Several methodologies have been proposed to assess the action of endodontic instruments on the canal walls. More recently, the use of computed tomography (CT) has been suggested for this purpose because it is a nondestructive method that allows measuring the amount of root dentin removed by endodontic instruments (4). The aim of this ex vivo study was to compare, using $\mathrm{CT}$, the direction of transportation in the apical third of mesiobuccal (MB) canals of maxillary molars prepared with manual, oscillatory and rotary techniques.

\section{MATERIAL AND METHODS}

The research protocol was approved by the Ethics Committee of the Lutheran University of Brazil (Protocol number 2005-040H).

Sixty extracted maxillary human molars with fully formed apices were obtained from the Tooth Bank of the University of Passo Fundo (Brazil) and stored in saline at $4^{\circ} \mathrm{C}$ until the moment of use. The teeth were selected in view of their similar characteristics of length (19 to $22 \mathrm{~mm}$ ) and curvature degree $\left(20\right.$ to $40^{\circ}$ ) by using the RadioImp software (Radiomemory, Belo Horizonte, MG, Brazil), according to the Schneider's method.

Access cavities were prepared and the MB canals were located and explored with a size $10 \mathrm{~K}$-file (Dentsply/ Maillefer, Ballaigues, Switzerland), which was passively advanced into the canal until its tip adjusted to the apical foramen. Real canal length was recorded and the working length (WL) was calculated by subtracting $1 \mathrm{~mm}$ from this measurement. Then, the teeth were embedded in acrylic resin blocks to facilitate their handling (4).

In order to compare the direction of the canal transportation, pre- and post-instrumentation crosssection CT images were obtained $3 \mathrm{~mm}$ short of the apical foramen by using the GE LightSpeed Plus multidetector CT scanner (General Electric Medical Systems, Milwaukee, WI, USA). This CT scanner provides $0.6-\mathrm{mm}$-thick axial sections with $0.6-\mathrm{mm}$ increments, a 0.8 -rpm tube and reconstruction tools for maximum intensity projection and volume rendering (volume reconstruction by intensity, 4D). The CT scans were made using the abdomen protocol supplied by the CT scanner, with a bone tissue window $(100 \mathrm{kV}$ and $150 \mathrm{~mA}$ ), $512 \times 512$ pixels matrix, 1.25 -mm-thick axial sections with $0.6-\mathrm{mm}$ increments, 0.625 pitch, $32-\mathrm{cm}$ display field of view and beam incidence at the central portion on the device used to fix the specimens.
Reconstruction of the 0.6-mm-thick axial sections was performed after obtaining pre-instrumentation CT scans of all teeth, which provided better image definition. The images were stored in the computer's hard disk for further comparison by specific software. The teeth were randomly assigned to 3 groups ( $n=20$ ), according to the technique used for root canal instrumentation:

Manual Technique. The MB root canals were instrumented using stainless steel K-Flexofiles (Dentsply/Maillefer) following the crown-down technique. The files were pre-curved according to root canal direction. Two roots of this group were lost due to acrylic resin penetration during tooth inclusion. The tooth/resin blocks were gripped in a clamping device, and the cervical and middle canal thirds were preflared using 32-mm-long sizes 1 and 2 Gates-Glidden (GG) drills (Dentsply/Maillefer) attached to a compressed airdriven handpiece ( $\mathrm{KaVo})$. A silicon stopper was placed on the GG drills to limit their penetration up to a point corresponding to the start of each MB root curvature, which had been previously determined by the initial radiograph. Thereafter, the root canals were irrigated and filled with sodium hypochlorite. A size $40 \mathrm{~K}$-Flexofile was passively introduced into the canals and moved from the right and to the left with a slight pressure toward the apex with a brushstroke action against the canal walls. Files of decreasing size were successively introduced into the canal until the WL was reached with a size 15 K-Flexofile. A size $10 \mathrm{~K}$-file was used at the WL between instruments. The apical third was prepared according to the step-back technique up to a size 30 file (master apical file [MAF]) at WL and stepping back with two subsequent instruments (sizes 35 and 40).

Oscillatory Technique. The MB canals were prepared using stainless steel K-Flexofiles attached to the handpiece of TEP E-16R oscillatory system (NSK Nakanishi). The headpiece was used with 16:1 speed reduction and was driven by an electric engine (TC 3000; Nouvag Ag, Switzerland) at 10,000 rpm, which resulted in a speed rotation of $625 \mathrm{rpm}$. The cervical and middle thirds were preflared in the same way as described for manual technique. The apical third was prepared according to the step-back technique up to a size 30 file (master apical file [MAF]) at WL and stepping back with two subsequent instruments (sizes 35 and 40).

Rotary Technique. The MB canals were prepared using ProTaper nickel-titanium rotary system (Dentsply/ Maillefer). The headpiece was used with 16:1 speed reduction and was powered by an electric engine (TC 
3000 ) with $4,000 \mathrm{rpm}$, resulting in an rotation of 250 rpm. Instrumentation started with S1 instrument up to the root curvature. Then, SX instrument was used at the same length and the instrumentation was completed with S1, S2, F1, F2, and F3 instruments up to the WL.

All canals were prepared by the same operator. During instrumentation, all canals were irrigated with $2 \mathrm{~mL}$ of $2.5 \%$ sodium hypochlorite and $2 \mathrm{~mL}$ of $17 \%$ ethylenediaminetetraacetic acid (EDTA; Farmácia Extratus, Passo Fundo, RS, Brazil) used alternately and at each change of file. Instruments were discarded after used in five canals. After instrumentation, the specimens were subjected to new CT scans, with the same preset parameter settings. The CT images were assessed by a calibrated dental radiology specialist blinded to the root canal preparation technique. Intra-examiner agreement was evaluated by remeasuring 20 percent of the sample, chosen at random, after a 1 week interval.

The images were exported to Adobe Photoshop software (version 7.0; Adobe Systems Inc, San Jose, CA, USA), converted to 8-bit RGB mode (256 colors) and the dentin area was selected with 32 gray-tone tolerance. Thereafter, the Gradient Map tool was selected by a left click of the mouse on the "Adjustments" submenu of "Image" menu. Then, the following commands were set: black color was used for the front plane; for background, yellow was used for the initial images (I) and green for the final images (F). Next, the black color was eliminated from the final image (green) and

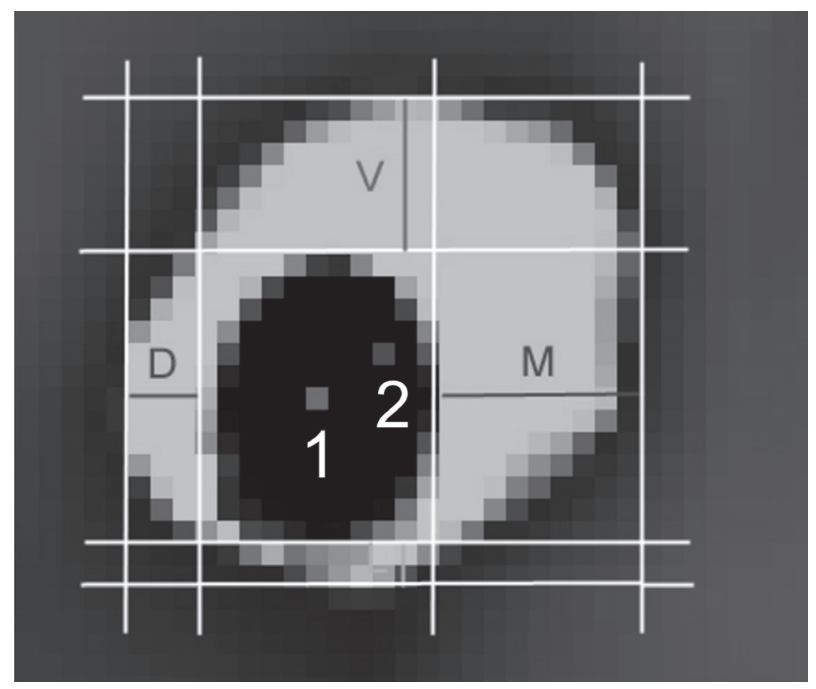

Figure 1. CT axial section of the apical third. The canal center was marked with a pixel number 1 (initial image) and a pixel number 2 (final image). Canal transportation was measured and its direction was recorded ( $\mathrm{D}=$ distal; $\mathrm{M}=$ mesial and $\mathrm{V}=$ buccal direction). it was superimposed over the initial image (yellow). To detect the root canal wall differences between both images, the final image was rotated over the initial image until their external contours coincided (4). Zoom was increased to $1,200 \%$ so that one pixel could be visually identified. Then the number of pixels was marked with a pixel number 1 (initial image) and a pixel number 2 (final image) (Fig. 1). The coincidence between the pixel number 1 and pixel number 2 indicated no canal transportation. When the pixels were not coincident, the distance between them was measured with the rulers tool under the "View" menu. The direction of root canal transportation produced by each instrumentation technique was determined in relation to the canal walls and was classified as buccal, palatal, medial, distal, distobuccal, distopalatal, mesiopalatal and mesiobuccal.

Data were analyzed statistically by two-way ANOVA and Tukey's test using SPSS software version 10.0.5 (SPSS Inc., Chicago, IL, USA). Significance level was set at $5 \%$.

\section{RESULTS}

Table 1 shows the means (in $\mathrm{mm}$ ) and standard deviation of canal transportation produced by manual and mechanical instrumentation techniques in the apical third according to the different directions toward

Table 1. Means (in $\mathrm{mm}$ ) ( \pm standard deviation) of canal transportation produced by each instrumentation technique in the apical third according to the direction of dentin removal towards the root curvature

\begin{tabular}{|c|c|c|c|}
\hline \multirow{2}{*}{ Direction } & \multicolumn{3}{|c|}{ Technique } \\
\hline & Manual & Oscillatory & Rotary \\
\hline Buccal & $0.27 \pm 0.14^{\mathrm{a}}$ & $0.51 \pm 0.21^{b}$ & $0.43 \pm 0.24^{\mathrm{ab}}$ \\
\hline Palatal & $0.28 \pm 0.21^{\mathrm{N} . S}$ & $0.37 \pm 0.17^{\text {N.S. }}$ & $0.27 \pm 0.16^{\mathrm{N} . \mathrm{S}}$ \\
\hline Mesial & $0.29 \pm 0.16^{\mathrm{N} . S}$ & $0.33 \pm 0.23^{\mathrm{N} . S}$ & $0.40 \pm 0.23^{\text {N.S. }}$ \\
\hline Distal & $0.24 \pm 0.12^{\mathrm{a}}$ & $0.52 \pm 0.23^{b}$ & $0.35 \pm 0.18^{\mathrm{a}}$ \\
\hline MB & $0.02 \pm 0.03^{\text {N.S. }}$ & $0.04 \pm 0.09^{\text {N.S. }}$ & $0.04 \pm 0.10^{\text {N.S. }}$ \\
\hline MP & $0.01 \pm 0.02^{\mathrm{a}}$ & $0.11 \pm 0.14^{\mathrm{b}}$ & $0.04 \pm 0.08^{\mathrm{ab}}$ \\
\hline DP & $0.01 \pm 0.03^{\mathrm{a}}$ & $0.12 \pm 0.23^{b}$ & $0.01 \pm 0.04^{\mathrm{a}}$ \\
\hline DB & $0.05 \pm 0.08^{\mathrm{N} . S}$ & $0.08 \pm 0.15^{\mathrm{N} . S}$ & $0.13 \pm 0.15^{\text {N.S. }}$ \\
\hline
\end{tabular}

Different letters in rows indicate statistically significant difference among the techniques at $5 \%$. N.S. $=$ nonsignificant at $5 \%$. MB $=$ mesiobuccal; $\mathrm{MP}=$ mesiopalatal; $\mathrm{DP}=$ distopalatal; $\mathrm{DB}=$ distobuccal. 
the root curvature. In the palatal, mesial, mesiobuccal and distobuccal directions there was no statistically significant difference $(p>0.05)$ between the techniques. On the other hand, significant differences $(p<0.05)$ were found among the techniques in the buccal, distal, mesiopalatal and distopalatal directions.

In the buccal direction, the manual technique $(0.27 \pm 0.14 \mathrm{~mm})$ produced significantly less canal transportation than the oscillatory technique $(0.51 \pm$ $0.21 \mathrm{~mm})(\mathrm{p}=0.004)$ and both were similar to the rotary technique $(0.43 \pm 0.24 \mathrm{~mm})(\mathrm{p}>0.05)$. In the distal direction, the oscillatory technique $(0.52 \pm 0.23 \mathrm{~mm})$ produced more canal transportation than manual $(0.24$ $\pm 0.12 \mathrm{~mm})$ and rotary $(0.35 \pm 0.18 \mathrm{~mm})$ techniques $(p=0.000)$, which were similar to each other $(p>0.05)$. In the mesiopalatal direction $(0.11 \pm 0.14 \mathrm{~mm})$, the oscillatory technique produced more canal transportation than the manual technique $(0.01 \pm 0.02 \mathrm{~mm})(\mathrm{p}=0.004)$, and both were similar to the rotary technique $(0.04 \pm$ $0.08 \mathrm{~mm})(\mathrm{p}>0.05)$. In the distopalatal direction, the oscillatory technique produced more canal transportation $(0.12 \pm 0.23 \mathrm{~mm})(\mathrm{p}=0.022)$ than the manual $(0.01 \pm$ $0.03 \mathrm{~mm})$ and the rotary $(0.01 \pm 0.04 \mathrm{~mm})$ techniques, which were similar to each other ( $p>0.05)$.

Pearson's correlation coefficient $(\alpha=1 \%)$ and the t-test for the paired samples $(\alpha=5 \%)$ revealed excellent agreement $(\mathrm{r}=0.997)$ with no significant difference $(\mathrm{p}=0.827)$.

\section{DISCUSSION}

The use of CT to evaluate the quality of root canal preparation has been shown to provide better results $(4,5)$ than other methods such as radiographic imaging (6).

MB root canals of extracted human maxillary molars were used in the present study because they usually present an accentuated curvature and mesiodistal flattening (7). These characteristics are additional shortcomings during chemomechanical instrumentation and make the cleaning and shaping of these canals even more difficult, mainly in the isthmus areas. The crowns were maintained in order to reproduce, as closely as possible, the routine clinical situation in endodontic practice, in which the interference of cervical dentin projections creates tensions on the endodontic files during root canal instrumentation $(8,9)$. The importance of cervical preflaring with GG drills on canal transportation has been underscored (8). The use of these drills for widening the cervical third and the more coronal portion of the middle third might reduce the excessive thinning of the canal walls, thus minimizing the negative influence of canal shape on endodontic instrumentation (4).

The oscillatory and rotary systems were powered by an electric engine because compressed air-driven systems do not allow torque control and may undergo air pressure variations that might affect the rotational speed and torque (10).

Peters et al. (11) used nondestructive highresolution scanning tomography to assess changes in canals prepared with either K-Files, Lightspeed or ProFile .04 rotary instruments. These authors concluded that variations in canal geometry before preparation had more influence on the changes during preparation than the techniques themselves. Consequently, studies comparing the effects of endodontic instruments on canal anatomy should also consider details of the preoperative canal geometry.

The findings of the present study disagree with those of Bergmans et al. (12), who reported similar results between two NiTi rotary instrument types (smooth flexible versus active tapered shaft design). In another study (13), the authors did not observe major procedural errors with the use of the ProTaper system for shaping root canals of varying preoperative canal geometry and concluded that these instruments may be more effective in shaping narrow root canals than wider ones. Kosa et al. (14) reported less canal transportation with oscillatory techniques with manual NiTi files compared with rotary techniques. Glosson et al. (3) and Gergi et al. (15) evaluated root canal preparation with different techniques and found that rotary NiTi instruments produced less canal transportation than stainless steel or NiTi hand files. These divergent results may be explained by methodological differences.

Greatest dentin removal was observed in the specimens prepared with the oscillatory technique and it occurred toward of the inner surfaces. This is an important finding because it indicates that this technique should be performed carefully even when employing ISO-certified .02 taper files. These results are in agreement with those of Paqué et al. (16), who reported that the pressure exerted on the instruments in oscillatory systems together with the cutting ability of stainless steel files may result in excessive dentin removal in critical areas.

The manual technique produced more canal transportation in the buccal, palatal, mesial and distal 
directions. Three of these directions are on the outside and one is on the inner side of the root curvature. This result shows that when stainless steel files are pre-curved in the crown-down technique and the MAF is a size 30 instrument, the instrumentation preserves the most critical areas. Additionally, hand instrumentation allows a greater control of file direction, which increases safety compared to the oscillatory technique, as shown in the present study and according with Zmener et al. (17).

The rotary technique produced more canal transportation in the buccal and mesial directions, which are on the outside of the curvature. Compared to the other groups, this finding indicates that rotary technique had a better performance regarding the safety for preparation of critical areas. This may be related to the shape of the ProTaper files, which have a triangular convex crosssection with a slightly negative angle and a partially active safe-ended tip that confers a greater dentin cutting ability with greater safety to these instruments (18). These results are consistent with those of Peters et al. (11), who reported that the canals were transported to the external surfaces of the canal center as well as to other directions, and those of Bergmans et al. (2), who found that transportation occurred toward the external surface of the curvature (to either mesiobuccal or mesiolingual) in canals prepared by rotary systems. In another study, however, ProTaper system removed more dentin toward the innerside of the root curvature with a significantly pronounced apical straightening effect (19).

The results of this study showed that CT scanning is an accurate and efficient method for assessment of root canal instrumentation techniques $(4,15)$ and permits the detection of procedural errors with more recourses for diagnosis (20). Further studies are required to provide more information about preparation techniques, new instruments and methodologies used to evaluate the action of endodontic instruments inside the root canal, aiming at solving the problems inherent to such an important and difficult phase of the endodontic therapy.

According to the methodology used and the obtained results, the following conclusions may be drawn: 1) all techniques produced canal transportation; 2) the oscillatory technique produced the greatest removal of root dentin toward the innerside of the root curvature (distal, distopalatal and mesiopalatal directions).

\section{RESUMO}

Este estudo utilizou a tomografia computadorizada (TC) para comparar o transporte do canal radicular nos canais mésiovestibulares de molares superiores preparados por diferentes técnicas. Sessenta molares superiores foram divididos em 3 grupos $(n=20)$ de acordo com a técnica utilizada para o preparo do canal radicular: instrumentação manual com limas K-Flexofile, limas K-Flexofile acopladas a um sistema oscilatório e sistema rotatório ProTaper. Imagens de TC pré e pós-instrumentação foram obtidas $3 \mathrm{~mm}$ aquém do forame apical e superpostas para comparar o transporte do canal. Os dados foram analisados estatisticamente pela Análise de Variância (ANOVA) e Teste de Tukey utilizando o software SPSS $(\alpha=0,05)$. Na direção vestibular, a técnica manual produziu significantemente menos transporte do canal radicular do que a técnica oscilatória $(\mathrm{p}<0,05)$ e ambas foram similares a técnica rotatória $(p>0,05)$. Nas direções distal e disto-palatina, a técnica oscilatória produziu mais transporte do canal radicular $(\mathrm{p}<0,05)$. $\mathrm{Na}$ direção mésio-palatina, a técnica oscilatória produziu mais transporte do canal radicular do que a técnica manual $(p<0,05)$, sendo que ambas foram similares à técnica rotatória $(p>0,05)$. Em conclusão, todas as técnicas produziram transporte do canal radicular e a técnica oscilatória produziu os maiores desgastes de dentina na direção interna da curvatura.

\section{REFERENCES}

1. Schilder H. Cleaning and shaping the root canal. Dent Clin North Amer 1974;18:269-296.

2. Bergmans L, Van Cleynenbreugel J, Beullens M, Wevers M, Van Meerbeek B, Lambrechts P. Smooth flexible versus active tapered shaft design using Ni-Ti rotary instruments. Int Endod J 2002;35:820-828.

3. Glosson CR, Haller RH, Dove SB, Del Rio CE. A comparison of root canal preparations using $\mathrm{Ni}-\mathrm{Ti}$ hand, $\mathrm{Ni}$-Ti engine driven, and K-flex endodontic instruments. J Endod 1995;21:146-151.

4. Hartmann MSM, Barletta FB, Fontanella VRC, Vanni, JR. Canal transportation after root canal instrumentation: a comparative study with computed tomography. J Endod 2007;33:962-965.

5. Versiani MA, Pascon EA, Sousa CJA, Borges MAG, Sousa-Neto MD. Influence of shaft design on the shaping ability of 3 nickeltitanium rotary systems by means of spiral computed tomography. Oral Surg Oral Med Oral Pathol Oral Radiol Endod 2008; 105:807813.

6. Sydney GB, Batista A, Melo LL. The radiographic platform: a new method to evaluate root canal preparation. J Endod 1991;17:570572.

7. Taşdemir T, Aydemir H, Inan U, Ünal O. Canal preparation with Hero 642 rotary Ni-Ti instruments compared with stainless steel hand $\mathrm{K}$-file assessed using computed tomography. Int Endod J 2005;38:402-408.

8. Vanni JR, Santos R, Limongi O, Guerisoli DMZ, Capelli A, Pécora JD. Influence of cervical preflaring on determination of apical file size in maxillary molars: SEM analysis. Braz Dent J 2005; 16:181186.

9. Duarte MAH, Bernardes RA, Ordinola-Zapata R, Vasconcelos BC, Bramante CM, Moraes IG. Effects of Gates-Glidden, LA Axxess and Orifice Shaper burs on the cervical dentin thickness and root canal area of mandibular molars. Braz Dent J 2011;22:28-31.

10. Limongi O, Klymus AO, Baratto Filho F, Vanni JR, Travassos R. In vitro evaluation of the presence of apical deviation with employment of automated handpieces with continuous for root canal preparation. J Appl Oral Sci 2004;12:195-199.

11. Peters OA, Laib A, Göhring TN, Barbakow F. Changes in root canal geometry after preparation assessed by high-resolution 
computed tomography. J Endodont 2001;27:1-6.

12. Bergmans L, Van Cleynenbreugel J, Beullens M, Wevers M, Van Meerbeek B, Lambrechts P. Progressive versus constant tapered shaft design using NiTi rotary instruments. Int Endod J 2003;36:288-295.

13. Peters OA, Peters CI, Schönenberg K, Barbakow F. ProTaper rotary root canal preparation: effects of canal anatomy on final shape analyzed by micro CT. Int Endod J 2003;36:86-92.

14. Kosa DA, Marshall G, Baumgartner JC. An analysis of canal centering using mechanical instrumentation techniques. J Endod 1999;25:441-445.

15. Gergi R, Rjeily JA, Sader J, Naaman A. Comparison of canal transportation and centering ability of twisted files, pathfileProTaper system and stainless steel hand K-files by using computer tomography. J Endod 2010;36:904-907.

16. Paqué F, Barbakow F, Peters OA. Root canal preparation with Endo-Eze AET: changes in root canal shape assessed by microcomputed tomography. Int Endod J 2005;38:456-464.
17. Zmener O, Pameijer CH, Banegas G. Effectiveness in cleaning oval-shaped root canals using anatomic endodontic technology, ProFile and manual instrumentation: a scanning electron microscopic study. Int Endod J 2005;38:356-363.

18. Paqué F, Musch U, Hülsmann M. Comparison of root canal preparation using $\mathrm{RaCe}$ and ProTaper rotary Ni-Ti instruments. Int Endod J 2005;38:8-16.

19. Vaudt J, Bitter K, Neumann K, Kielbassa AM. Ex vivo study on root canal instrumentation of two rotary nickel-titanium systems in comparison to stainless steel hand instruments. Int Endod J 2009;42:22-33.

20. Alencar AH, Dummer PM, Oliveira HC, Pécora JD, Estrela C. Procedural errors during root canal preparation using rotary NiTi instruments detected by periapical radiography and cone beam computed tomography. Braz Dent J 2010;21:543-549.

Received January 11, 2010 Accepted April 6, 2011 